\section{Cardiopulmonary Arrest Survival Related to Hospital Discharge in Adults} ORIGINAL

\section{Abstract}

Objective: To analyze the characteristics of patients surviving from a Cardiopulmonary Arrest (CPA) and identify factors related to the survival to hospital discharge in adults.

Method: Analytical, prospective, quantitative study, developed in a tertiary public hospital in Campo Grande, the capital of Mato Grosso do Sul, Brazil, in the adult, general and cardiac ICU.

Results: 78 survivors of CPA were evaluated, 38.5\% had hospital discharge, all showed only one CPA event, while those who evolved to death had two or more events. There was an association between the number of CPA and the outcome, and the relationship between the use of vasoactive drugs and kidney failure with death.

Conclusion: CPA remains a survival event and outcome variables. Currently, there are no prognostic models able to identify which patients would not benefit from resuscitation. Studies on this topic must be multiplied to increase knowledge on the subject and contribute to current statistics scarce, and increase understanding of these events.

\section{Introduction}

Despite advances in recent years related to the prevention and treatment of Cardiopulmonary Arrest (CPA), this event remains a global public health problem, and many lives are lost annually. Even there is not an exact scale of the problem by the small number of statistical studies; it is estimated 200,000 events per year in Brazil. Half of these events occur in hospitals and other environments such as homes, malls, airports, stadiums, etc. [1].
Daiana Terra Nacer ${ }^{1}$, Marisa Dias Rolan Loureiro", Anna Letícia Miranda², Isabelle Campos de Azevedo ${ }^{3}$, Marcos Antonio Ferreira Júnior ${ }^{3}$

1 Departamento de Enfermagem, Centro de Ciências Biológicas e da Saúde, Universidade Federal de Mato Grosso do Sul, Campo Grande/MS, Brasil.

2 Hospital das Clínicas de Minas Gerais, Universidade Federal de Minas Gerais, Belo Horizonte/MG, Brasil.

3 Departamento de Enfermagem, Centro de Ciências da Saúde, Universidade Federal do Rio Grande do Norte, Natal/ RN, Brasil.

\section{Contact information:}

\section{Marcos Antonio Ferreira Júnior.}

Address: Universidade Federal do Rio Grande do Norte, Centro de Ciências da Saúde, Departamento de Enfermagem. Avenida Salgado Filho, S/N, Lagoa Nova, Natal/RN, Brasil. CEP: 59078970.

Đmarcos_nurse@hotmail.com

\section{Keywords}

Heart Arrest; Cardiopulmonary Resuscitation; Survival. 
Data on CPA survival are used to audit the performance of the professionals involved in the care and help to determine whether new resuscitation techniques are effective. Improvements in results depend on rigorous research into the effectiveness of critical interventions that are made during the basic support and advanced life [2].

The American Heart Association (AHA) published in 2010 the Update the CPR Guidelines (Cardiopulmonary Resuscitation) and Emergency Cardiovascular Care (ACE) reporting considerable variation in the incidence and outcomes of reported CPA in the United States of America (USA) in different regions. It revealed the need for health services to identify and assess each event, as a suggestion to improve survival rates [3].

With the publication of the current guidelines in 2015, the AHA reaffirmed this variation so the services should establish an ongoing evaluation to improve services including systematic evaluation, feedback, measuring or comparative evaluation and analysis [4].

A study showed differences in survival and neurologic outcomes in patients after CPA in nearby regions and suggested that regional disparities in the pre-hospital and post-resuscitation care service may be the explanation for the differences found [5].

When considering the relevance of the topic and the importance of the collection of statistical data on the subject, this study was developed to analyze the characteristics of patients surviving CPA and identify factors related to survival to hospital discharge in adults.

\section{Method}

This study is analytical and prospective with a quantitative approach, developed in a tertiary public hospital in the city of Campo Grande, the capital of Mato Grosso do Sul, midwestern Brazil, from November 2014 to May 2015 in adult, general and cardiology ICU, with 78 CPA survivors.
The study included all adult patients, CPA survivors hospitalized in the units eligible for the study during the period of data collection. Data were collected from electronic medical records and patients identified by daily visits to the research place during the study period.

Exclusion criteria were patients younger than eighteen, of indigenous groups, maroon, pregnant women and/or deprived of freedom. There were also excluded cases where it was not possible to collect data for lack of information. There were no patients excluded.

After data collection, they were stored in spreadsheets Microsoft Office Excel®. Statistical analysis was performed using SPSS, version 22.0, adopting a significance level of $5 \%$.

The evaluation of the association between the evolution of the patients and the place of the CPA was performed using the chi-square test. As for the qualitative variables age, gender, previous diseases, cause of hospitalization, length of stay, number of CPA, CPR cycles and heart rate were associated with the outcome for establishing the value of $p$ using the chi-square test, the chi-square test with Bonferroni correction or the Mann-Whitney test, according to the nature of each variable. The other results of this study are presented by descriptive statistics or in tables.

This research was by Resolution $N^{\circ} 466$, of December 12, 2012, of the National Health Council of the Ministry of Health of Brazil, adopted in its ethical and methodological aspects by the Ethics Committee of the Federal University of Mato Grosso do Sul, under Opinion Nº 856096 of 11.02.2014.

\section{Results}

This study evaluated 78 patients surviving when $56.4 \%$ of those had the first event in the intrahospital environment. Regarding the evolution, $38.5 \%$ had the hospital discharge. The data on the evolution of the patients are described in Table 1. 
Table 1. Relationship between the evolution of the patients and the place of occurrence of Cardiopulmonary Arrest. Campo Grande/ MS, 2015 ( $n=78)$.

\begin{tabular}{|c|c|c|c|c|c|}
\hline \multirow{3}{*}{ Evolution } & \multicolumn{4}{|c|}{ Place } & \multirow{3}{*}{ P value* } \\
\hline & \multicolumn{2}{|c|}{$\begin{array}{l}\text { Extra hospital } \\
\qquad(n=34)\end{array}$} & \multicolumn{2}{|c|}{$\begin{array}{l}\text { Intra hospital } \\
\qquad(n=44)\end{array}$} & \\
\hline & N & $\%$ & $\mathrm{~N}$ & $\%$ & \\
\hline Discharge & 15 & 44.1 & 15 & 34.1 & \multirow{3}{*}{0.367} \\
\hline Death & 19 & 55.9 & 29 & 65.9 & \\
\hline Total & 34 & 100.0 & 44 & 100.0 & \\
\hline
\end{tabular}

The Table 2 shows the clinical and epidemiological variables of the study subjects and their relationship with the hospital discharge and death outcomes, as follows:

Table 2. Relationship between the clinical and epidemiological variables of the subjects and the hospital discharge and death outcomes. Campo Grand /MS, 2015 ( $n=78)$.

\begin{tabular}{|c|c|c|c|c|}
\hline \multirow[b]{2}{*}{ Factors } & \multicolumn{2}{|c|}{ Evolution } & \multirow{2}{*}{$\begin{array}{c}\text { P } \\
\text { value* }\end{array}$} & \multirow{2}{*}{$\begin{array}{l}\text { Total } \\
(n=78)\end{array}$} \\
\hline & $\begin{array}{l}\text { Discharge } \\
(n=30)\end{array}$ & $\begin{array}{l}\text { Death } \\
(n=48)\end{array}$ & & \\
\hline Age & $57.83 \pm 2.70$ & $64.75 \pm 2.82$ & 0.057 & $62.09 \pm 2.05$ \\
\hline \multicolumn{5}{|l|}{ Gender } \\
\hline Female & $40.0(12)$ & $45.8(22)$ & \multirow{2}{*}{0.613} & $43.6(34)$ \\
\hline Male & $60.0(18)$ & $54.2(26)$ & & $56.4(44)$ \\
\hline \multicolumn{5}{|c|}{ Previous diseases } \\
\hline Hypertension & $40.0(12)$ & $47.9(23)$ & 0.494 & $44.9(35)$ \\
\hline Cardiac & $23.3(7)$ & $20.8(10)$ & 0.795 & $21.8(17)$ \\
\hline $\begin{array}{l}\text { Diabetes } \\
\text { mellitus }\end{array}$ & $13.4(4)$ & $20.8(10)$ & 0.401 & $17.9(14)$ \\
\hline COPD** & $16.7(5)$ & $12.5(6)$ & 0.607 & $14.1(11)$ \\
\hline Neuropathy & $13.3(4)$ & $14.6(7)$ & 0.877 & $14.1(11)$ \\
\hline Kidney failure & $6.7(2)$ & $14.6(7)$ & 0.287 & $11.5(9)$ \\
\hline Other & $20.0(6)$ & $10.4(5)$ & 0.237 & $14.1(11)$ \\
\hline
\end{tabular}

\begin{tabular}{|c|c|c|c|c|}
\hline \multirow[b]{2}{*}{ Factors } & \multicolumn{2}{|c|}{ Evolution } & \multirow{2}{*}{$\begin{array}{c}\text { P } \\
\text { value* }\end{array}$} & \multirow{2}{*}{$\begin{array}{c}\text { Total } \\
(n=78)\end{array}$} \\
\hline & $\begin{array}{l}\text { Discharge } \\
(n=30)\end{array}$ & $\begin{array}{l}\text { Death } \\
(n=48)\end{array}$ & & \\
\hline \multicolumn{5}{|c|}{ Main causes for hospitalization } \\
\hline Infection & $10.0(3)$ & $22.9(11)$ & 0.148 & 17.9 (14) \\
\hline Cardiac & $13.3(4)$ & $20.8(10)$ & 0.592 & $17.9(14)$ \\
\hline Trauma & $13.3(4)$ & $16.7(8)$ & 0.941 & $15.4(12)$ \\
\hline $\begin{array}{l}\text { Acute } \\
\text { myocardial } \\
\text { infarction }\end{array}$ & $23.3(7)$ & $6.3(3)$ & 0.028 & $12.8(10)$ \\
\hline $\begin{array}{l}\text { Days of } \\
\text { hospitalization }\end{array}$ & $36.43 \pm 6.70$ & $23.46 \pm 3.34$ & 0.038 & $28.45 \pm 3.35$ \\
\hline
\end{tabular}

Risk factors for complications

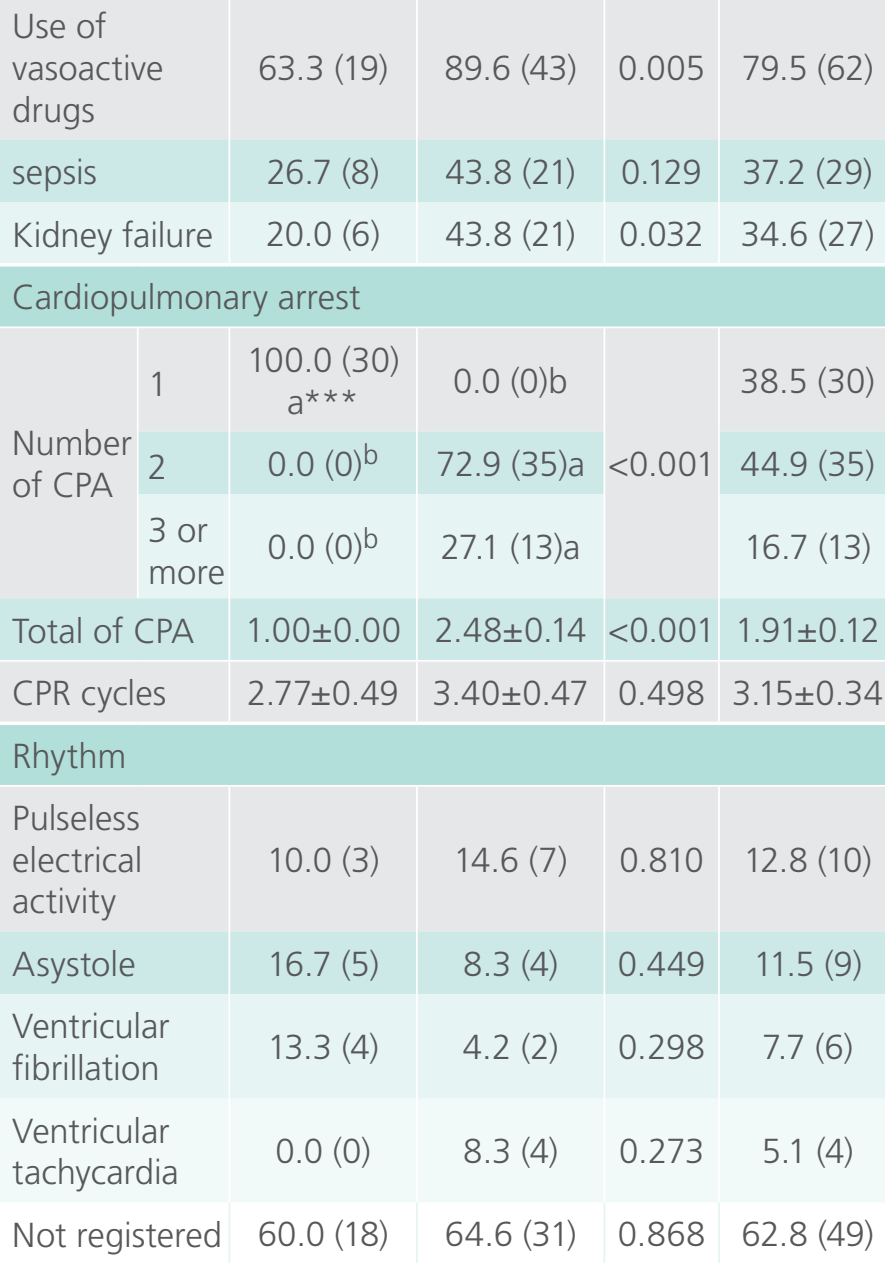

The results are shown in mean \pm standard deviation and frequencies. * P-values: were calculated using the Mann-Whitney test or chi-square test. ${ }^{* *}$ : COPD: chronic obstructive pulmonary disease. ${ }^{* * *}$ : Different letters on the lines indicate a significant difference between discharge and death on the chi-square test with Bonferroni correction. 


\section{Discussion}

Regarding the place occurring CPA, this study found no significant differences between the intra and extra-hospital settings and outcomes of discharge and death. A study from Norway showed similar data, where out of 380 reanimations, $40.6 \%$ were intra-hospital and $59.4 \%$ were extra hospital, finding survivals in the discharge of $16.2 \%$ and $16.8 \%$, respectively. The authors concluded that the outcomes were similar for both the study scenarios [6].

In 2012, the AHA published statistics of heart disease and stroke of the United States of America (USA), highlighting an incidence rate of CPP of 359,400 extra hospital events compared to 209,000 of intra-hospital events, with a survival rate of only 9.5\% for extra-hospital settings. [7]

The differences between the cited articles reinforce the known variations between regions and services and demonstrate the need for more comparisons involving different scenarios and services to explore the causes. The incidence and outcome of CPA vary widely between countries and continents. Thus, a better understanding of this variability is fundamental to the success rates be known and improved [8].

Extra-hospital CPA survival rates in the USA have improved substantially since 2005 . This performance was attributed to improvements in pre-hospital and in-hospital care [9]. In a large national resuscitation record in this country, the overall rate of survival to discharge was $17 \%$ and significantly improved for ten years. In the survey period, the annual survival increased from $13.7 \%$ to $22.3 \%$ [10].

These data reinforce the need for each institution to frequently assess the results and know its profile so they can set goals, implement strategies, improvements and monitor their progress. Comparisons between the different institutions and regions are also valid, but must be carried out according to features and known differences.

In a study conducted in a state in Northeast of Brazil, 107 patients survived from CPR, 55 of them were female and 52 were male, with no statistically significant differences for this variable, and average age of 54 years old [11]. When compared to this study, there were more male and the average age was 62 years old.

As in the study mentioned above that age and gender were not related to the success of resuscitation, the results of this research could not establish a statistically significant relationship between these factors and hospital discharge. According to the authors, there is no evidence that only the age is an important prognostic factor in post-resuscitation survival. Therefore, it is not an isolated criterion to contraindicate resuscitation in the elderly presenting CPA. As for the underlying diseases, according to the author, they can act as confounding factors, given that there is a tendency that as older, there is a higher number of comorbidities [11].

The results of this study converge with the data in the literature to show that the variables age and gender should not be factors used alone to decide on when to end resuscitation efforts.

Among the main diseases, the most frequently found was hypertension (44.9\%), however, it was not possible not establish any relationship between these diseases and a lower chance of survival.

A national study [11] found an incidence of immediate survival in patients without main diseases of about $10 \%$ and $27 \%$ in those who had at least one. The same study concluded that the presence of main diseases is considered in the literature as the variable that in isolation, it has the highest prognostic strength in patient survival. Also, it attributed the disagreement of its results with those of other research to some reasons such as highly complex evaluation of resuscitation; diversity of populations studied; varied etiologies with different degrees of severity; various causes of hospitalization, where they are often underestimated and not reported; the same way that the data of this study. However, few studies involving CPA related comorbidities with survival. 
In AHA guidelines on the CPR records, the intra-hospital, the "Utstein style", published in 1997 and still used as a reference for the records of resuscitation efforts have cited the lack of studies and recommended such registration. According to that article, comorbidities have a powerful influence on the outcome of patients treated with extra-hospital ventricular fibrillation. It is strongly recommended recording the presence of the most important comorbidities, since the probability that strongly influence the resuscitation results to have a high degree of validity. There is no single method validated to describe them in hospitalized patients, but it is known for its importance in this context [12].

The CPA and the science of resuscitation still have major issues to be resolved, although its effectiveness has already been confirmed over time by important societies such as AHA, being undeniable the need for more studies relating comorbidities and the success of resuscitation.

Regarding the length of stay, this study found a statistically significant relationship between this variable and the outcome of patients, with a mean of $36.43 \pm 6.70$ days of hospitalization for patients who had discharge and $23.46 \pm 3.34$ for patients who died during hospitalization $(p=0.038)$.

Hospitalization in the intensive care unit (ICU) is most frequent in critically ill patients already on admission and is associated with a higher rate of hospital mortality [13]. Few studies relate the total time of admissions to the survival or death after cardiac arrest. The National Resuscitation Register of USA [14] found an average length of hospitalization after a nearly two weeks of CPA event for survivors and less than two days for those who die in the hospital. Although this present study has found higher hospitalization time, they converge with the USA above data, because survivors have gone through periods of longer hospital stays.

It is believed that this fact is justified by the expected severity of post-CPA patients, who require more ICU service time and after discharge from the sector require a longer period of recovery.

Regarding the use of vasoactive drugs (VAD), its use was found in $79.5 \%$ of patients throughout the hospital stay, while $34.6 \%$ of patients had renal failure (acute and/or chronic). Both factors were statistically related to higher probability of death.

When assessing the hemodynamic status of 165 survivors of extra-hospital CPA due to cardiac causes, who were admitted to the ICU, a study found hemodynamic instability that required vasoactive drugs in $54.5 \%$ of patients during the first 72 hours after resuscitation. Significant increases in plasma creatinine dosages and decreased urine output were also observed in the group [15].

The association of renal and cardiovascular dysfunction has a worse prognosis for patients after CPA, regardless of other factors such as age, comorbidities or severity of the disease [16].

Despite methodological differences between studies hindering accurate comparisons, together with the scarcity of current studies, it is possible to relate the use of VAD and renal failure with poor prognosis for these patients. This association found indicates the need for more studies to develop scores able to assess which patients would benefit or not resuscitation. Renal failure and the use of VAD probably would present major impact on this score.

Regarding the number of CPA events per patient, this study found that $44.9 \%$ of patients had two events during hospitalization. The National Registry of Cardiopulmonary Resuscitation of the USA has 14,720 adult patients, which showed that $92 \%$ of patients had only one CPA event, 7\% had two, and $1 \%$ had three events [14].

The duration of resuscitation efforts in the records used for data collection of this research was by the number of CPR cycles and not in minutes, a fact that is due to greater ease of measurement and the absence of specific documents for the registration of resuscitation, both extra as intra-hospital care services, research scenario of this study. 
However, in AHA guideline on CPR records, "Utstein style" recommends the use of time in minutes of the CPR, time recognition of the event, start time and end of resuscitation [12].

This study found an average of 3.15 CPR cycles in the first event, with 2.77 cycles for patients who developed hospital discharge and 3.40 cycles for patients that died. Although not obtained a statistically significant difference $(p=0.498)$, patients who died had a greater length of CPR, the same as in another study in southern Brazil [17].

It was possible to calculate the ratio between the number of CPA suffered and the evolution of the cases in this study, when the average total CPA was 1.91 events per patient, with one event per patient for those who developed hospital discharge and 2.48 for those who died. All those who had hospital discharge had only one event, while all who died had two or more events, with a statistically significant relationship to the outcome about this variable $(p<0.001)$.

Another study evaluated 203 intra-hospital resuscitations when only $8.5 \%$ of the survivors who had hospital discharge had suffered more than a CPA, as among those who progressed to $37.8 \%$ death suffered more than a CPA $(p<0.001)$ [18].

This issue raises an important ethical issue and the need for discussions by the multidisciplinary team on efficiency and non-maleficence of large numbers of resuscitation, considering that there were resuscitated patients for up to six times in this study.

It should also be observed the erosion of staff providing direct patient care in subsequent resuscitation. In a study [19] conducted to assess the stress of ICU nurses to interview the participants' actions considered most stressful, there were "doing things with minimum available time" and "face the death of the patient," considered strong stressors.

It is a controversial point, which crosses the field of ethics, based on issues such as dysthanasia and should prompt professionals to reflect on how often a patient should be resuscitated and from that point the interventions come to prolong the suffering, without benefits to the patient and can cause suffering staff.

In the initial pace of CPR, the most identified in this study were those non-shockable: pulseless electrical activity (PEA) (12.5\%), followed by Asystole (11.5\%). It was not possible to relate a specific rhythm with the greatest chance of success statistically because in $62 \%$ of the records were not registered.

Because it is a dynamic event, often important CPA information may be lost through lack of use of specific records. It is believed that even there was a relation between the initial rate of CPA and survival because it is an underreported result, this condition indicates the need to use records Utstein Style.

Problems relating to records are common. A study found a situation like this study to analyze 136 patients admitted to the ICU, who had suffered CPA. Non-shockable rhythms prevailed, with $15.4 \%$ of asystole, but in $43.4 \%$ of cases, the initial CPR mechanism could not be determined by the medical records. When comparing survivors to non-survivors, there was higher mortality in asystole group, but it was not possible to associate a pace greater chance of survival, a condition that was also attributed to underreporting the initial rhythm [20].

However, concerning the cause of hospitalization, the patients of this study were hospitalized due to acute myocardial infarction (AMI), having a statistically greater chance of survival $(p=0.028)$ when compared to hospital infections, trauma or other diseases.

The outcome of the CPA is always better when the first monitored rhythm is shockable instead of non-shockable rhythms. The survival rates vary from $18 \%$ to $64 \%$ to Ventricular Fibrillation (VF)/Ventricular Tachycardia (VT) and from $1.2 \%$ to $14 \%$ for asystole and PEA. Rhythms of VF/VT can be treated quickly and with successful defibrillation. Furthermore, since these rhythms asystole to deteriorate 
rapidly if not treated the presence of a VF/VT implies a recent onset of CPA [21].

These rhythms are common when ischemia is the precipitating cause of the CPA. In hospital cohorts that showed a high percentage of patients with ischemic heart disease, the prevalence of VF/VT was high and more than 50\% [21].

\section{Conclusion}

The PCR remains a survival event and outcome variables. Despite the limitations of this study, as the CPA non-standard records and difficult comparisons due to different methods in existing jobs and few current articles for comparisons, some factors might be related.

The number of CPA events, the use of vasoactive drugs and renal failure could be associated with poor prognosis for patients. However, longer hospital stays and AMI as its cause were associated with higher odds of discharge.

There are currently no prognostic models able to identify which patients do not benefit from resuscitation efforts before the meeting. The objective is to prevent the maneuvers become procedures that prolong the suffering and lead to long periods of hospitalization, high costs and little chance of survival or even sequels.

The complexity of care during CPR and post-CPR are demonstrably known. The technical and scientific advances and early intervention had a better chance of survival. However, there are still major challenges to be overcome. Therefore, more studies are needed for the analysis of each of the clinical, epidemiological and outcomes variables found, with larger and more diverse populations, so that it can identify the relationship of each of the prognosis of resuscitated patients, and thus, develop scores for the decision to start or suspend the resuscitation efforts based on scientific evidence.

Finally, the findings of this study should provide subsidies to health professionals who work with critically ill patients in moments of decision to discontinue resuscitation efforts.

\section{References}

1. Sociedade Brasileira de Cardiologia. I Diretriz de Ressuscitação Cardiopulmonar e Cuidados Cardiovasculares de Emergência da Sociedade Brasileira de Cardiologia. Arq Bras Cardiol. 2013; 101(supp. 3):1-221.

2. King BP, d'Agapeyeff A, Gabbott DA. Inconsistencies in cardiac arrest reporting. Resuscitation. 2006; 68(1):85-91.

3. American Heart Association. Highlights of the 2010 American Heart Association Guidelines Update for CPR and ECC. 2010. Available from: https://www.heart.org/idc/groups/heartpublic/@wcm/@ecc/documents/downloadable/ucm 317350. pdf

4. American Heart Association. Highlights of the 2015 American Heart Association Guidelines Update for CPR and ECC. 2015. Available from: https://eccguidelines.heart.org/wp-content/ uploads/2015/10/2015-AHA-Guidelines-Highlights-English.pdf

5. Hasegawa K, Tsugawa Y, Camargo CA Jr, Hiraide A, Brown DF. Regional variability in survival outcomes of out-of-hospital cardiac arrest: the All-Japan Utstein Registry. Resuscitation. 2013; 84(8):1099-107.

6. Buanes EA, Heltne JK. Comparison of in-hospital and out-ofhospital cardiac arrest outcomes in a Scandinavian community. Acta Anaesthesiol Scand. 2014; 58(3):316-22.

7. Go AS, Mozaffarian D, Roger VL, Benjamin EJ, Berry JD, Borden WB, et al. Heart Disease and Stroke Statistics-2013 Update A Report From the American Heart Association. Circulation. 2013; 127(1):e6-e245.

8. Berdowski J, Berg RA, Tijssen JG, Koster RW. Global incidences of out-of-hospital cardiac arrest and survival rates: Systematic review of 67 prospective studies. Resuscitation. 2010; 81(11):1479-87.

9. Chan PS, McNally B, Tang F, Kellermann A; CARES Surveillance Group. Recent Trends in Survival From Out-of-Hospital Cardiac Arrest in the United States. Circulation. 2014; 130(21):1876-82.

10. Girotra S, Nallamothu BK, Spertus JA, Li Y; Krumholz HM, Chan PS. Trends in Survival After In-Hospital Cardiac Arrest. N Engl J Med. 2012; 367(20):1912-1920.

11. Gomes AMCG, timerman A, Souza CAM, Mendes CMC, Póvoas Filho HP, Oliveira AM, et al. In-Hospital Post-CardiopulmonaryCerebral Resuscitation Survival Prognostic Factors. Arq. Bras. Cardiol. 2005; 85(4):262-71. 
12. Cummins RO, Chamberlain D, Hazinski MF, Nadkarni V, Kloeck W, Kramer E, et al. Recommended guidelines for reviewing, reporting, and conducting research on in-hospital resuscitation: the in-hospital 'Utstein style'. A statement for healthcare professionals from the American Heart Association, the European Resuscitation Council, the Heart and Stroke Foundation of Canada, the Australian Resuscitation Council, and the Resuscitation Councils of Southern Africa. Resuscitation. 1997; 34(2):151-83.

13. Abelha FJ, Castro MA, Landeiro NM, Neves AM, Santos CC. Mortality and Length of Stay in a Surgical Intensive Care Unit. Rev Bras Anestesiol. 2006; 56(1):34-45.

14. Peberdy MA, Kaye W, Ornato JP, Larkin GL, Nadkarni V, Mancini $\mathrm{ME}$, et al. Cardiopulmonary resuscitation of adults in the hospital: A report of 14720 cardiac arrests from the National Registry of Cardiopulmonary Resuscitation. Resuscitation. 2003; 58(3):297-308.

15. Laurent I, Monchi M, Chiche JD, Joly LM, Spaulding C, Bourgeois $B$, et al. Reversible myocardial dysfunction in survivors of out-ofhospital cardiac arrest. J Am Coll Cardiol. 2002; 40(12):2110-6.

16. Okamoto TY, Dias JCY, Taguti P, Sacon MF, Kauss IAM, Carrilho CMDM, et al. Acute renal injury in patients with severe sepsis: prognostic factors. Scientia Medica. 2012; 22(3):138-41.

17. Bartholomay E, Dias FS, Torres FA, Jacobson P, Mariante A, Wainstein $R$, et al. Impact of Cerebral Cardiopulmonary Resuscitation Maneuvers in a General Hospital. Prognostic Factors and Outcomes. Arq. Bras. Cardiol. 2003; 81(2):189-95.

18. Chica RD, Colmenero M, Chavero MJ, Muñoz V, Tuero G, Rodríguez M. Factores pronósticos de mortalidad en una cohorte de pacientes con parada cardiorrespiratoria hospitalaria. Med. Intensiva. 2010; 34(3):165-9.

19. Guerrer FJL. Estresse dos enfermeiros que atuam em unidades de terapia intensiva do Brasil. 2007. Dissertação (Mestrado em Enfermagem na Saúde do Adulto) - Escola de Enfermagem, Universidade de São Paulo, São Paulo; 2007. Available from: http://www.teses.usp.br/teses/disponiveis/7/7139/tde20042007-102303/pt-br.php
Publish in International Archives of Medicine

International Archives of Medicine is an open access journal publishing articles encompassing all aspects of medical science and clinical practice. IAM is considered a megajournal with independent sections on all areas of medicine. IAM is a really international journal with authors and board members from all around the world. The journal is widely indexed and classified Q1 in category Medicine. 